\title{
Non-asphyxiating tracheobronchial foreign bodies in adults
}

\author{
R-S. Lan
}

Non-asphyxiating tracheobronchial foreign bodies in adults. R-S. Lan. CERS Journals Ltd 1994.

ABSTRACT: The presentations of 47 adult patients with a non-asphyxiating tracheobronchial foreign body were reviewed. The duration of residence of the foreign body was 1 week or less in nine ("acute group"); 1 month or more in 29 ("chronic group"), uncertain in four ("uncertain group"); and the foreign body was a broncholith in five patients ("broncholith group"). In the chronic and uncertain groups, no precipitating factor was found and bone was the most common foreign body. In the chronic group, a choking history was obtained before bronchoscopy in only 15 patient.

Clinical manifestations and roentgenograms were nonspecific in most cases, except in the acute group. In the chronic group, the mean duration of residence of the foreign body was 25.8 months. The diagnosis was delayed due to absence of a choking history and invisibility of the foreign body on chest films in 12 , due to patient's ignorance in 14 , due to physician's ignorance in 1 , and due to previous unsuccessful retrieval attempts in 2 patients.

The main indication for bronchoscopy in the acute group was a choking history or a visible foreign body on the chest film. In the chronic group, a choking history or conditions leading to "suspicion of an endobronchial lesion" were the main indications. The foreign body was removed with a fibreoptic bronchoscope in over $\mathbf{9 0 \%}$ of patients. It is concluded that the most important diagnostic factor is a high clinical index of suspicion and that flexible fibreoptic bronchoscopy provides a valuable therapeutic option in selected conditions.

Eur Respir J., 1994, 7, 510-514.
Section of Thoracic Medicine, Dept of Medicine, Chang Gung Memorial Hospital, Taipei, Taiwan.

Correspondence: R-S Lan

Section of Thoracic Medicine Dept of Medicine

Chang Gung Memorial Hospital

199 Tung Hwa North Road

Taipei

Taiwan

Keywords: Foreign bodies

Received: June 31993

Accepted after revision October 31993
In 1897, Killian [1] reported the first case of bronchoscopic removal of a bony foreign body in the bronchus. Later, in the premodern era, contributions were made by JACKSON and others [2-7] concerning non-asphyxiating tracheobronchial foreign bodies. New antimicrobial agents and the introduction of the clinical use of flexible fibreoptic bronchoscopy have made it difficult to compare these earlier reports cases with current cases. Review of the literature reveals only one large scale report [8], comprising mostly acute aspiration cases, and some casereports [9-26] on this topic in adults in the last four decades. To redefine the clinical spectrum of this syndrome in adults, with emphasis on chronic cases, I report my 13 yr experience with 47 adult cases.

\section{Methods}

During the past 13 yrs, in Chang Gung Memorial hospital, there were 47 adult patients (over 15 yrs of age) who had non-asphyxiating foreign bodies in the tracheobronchial tree. All of their medical charts, roentgenograms, and bronchoscopic reports were reviewed. They were classified into four groups (table 1). The "acute group" included patients with retention of the foreign body for less than 1 week. The "chronic group" consisted of the patients who had a foreign body for more than 1 month, as estimated by the history of choking or by the onset of respiratory symptoms. In the "uncertain group", the duration of retention of the foreign body could not be clinically determined. In the "broncholith group", the foreign body was endogenous calcifying material instead of inhaled matter.

Table 1. - Clinical characteristics

\begin{tabular}{lrlc}
\hline & Pts & Age & Sex \\
& $\mathrm{n}$ & Yrs & M/F \\
\hline Acute & 9 & $41 \pm 18$ & $9 / 0$ \\
Chronic & 29 & $51 \pm 14$ & $19 / 10$ \\
Uncertain & 4 & $60 \pm 8$ & $3 / 1$ \\
Broncholith & 5 & $59 \pm 23$ & $4 / 1$ \\
Total & 47 & $51 \pm 17$ & $35 / 12$ \\
\hline
\end{tabular}

Age data are presented as mean \pm sD. Pts: patients; M: male; F: female. 
All patients underwent flexible fibreoptic bronchoscopy under topical anaesthesia via nose, mouth or a previously installed endotracheal or tracheostomy tube, with spontaneous breathing or mechanical ventilation. Once the foreign body was recognized, an attempt was made to remove it with suction, teeth-forceps, cup-forceps, clawforceps, or a metal wire basket through the channel of the bronchoscope. If the initial trial was unsuccessful because the foreign body was embedded in the granulations, the granulations were removed as much as possible with biopsy forceps and the patient was then prescribed antibiotics. One week later the bronchoscopy was repeated to remove the foreign body.

\section{Results}

As shown in table $1,70 \%$ of the patients were in the chronic and uncertain groups, whilst the acute group had nine and the broncholith group had five patients. Ages ranged from 19-80 yrs. Males predominated in every group. Six patients in the acute group and one patient in the chronic group had been intubated for various clinical conditions (coma after traffic accident in six, coma due to sepsis in one) before the foreign body was found. It was possible that the foreign body came into the airway during intubation. Another patient in the acute group had a lead wire slipped into his tracheostomy in an iatrogenic accident. In the chronic group, one patient aspirated a plastic ballpen-cap during a seizure attack. None of the others had neuromuscular or swallowing disorders, nor could abuse of alcohol or sedatives be detected that could have precipitated foreign body aspiration.

\section{Clinical presentation (table 2)}

In the acute group, all three conscious patients volunteered an aspiration history. In the chronic group, only one patient volunteered a choking history, although we

Table 2. - Clinical manifestations in the 4 groups

\begin{tabular}{lcccc}
\hline & Acute & Chronic & \multicolumn{2}{c}{ Uncert Bronch } \\
& $\mathrm{n}=9$ & $\mathrm{n}=29$ & $\mathrm{n}=4$ & $\mathrm{n}=5$ \\
\hline Positive history* - total & 3 & 22 & 0 & 1 \\
$\quad$ Before diagnosis & & 15 & & \\
$\quad$ After diagnosis & & 7 & & \\
Cough & - & 29 & 4 & 4 \\
Sputum production & - & 20 & 3 & 2 \\
Fever, chill & - & 16 & 2 & 2 \\
Shortness of breath & - & 12 & 2 & 1 \\
Body weight loss & - & 9 & 3 & 2 \\
Chest pain & - & 9 & 2 & 1 \\
Haemoptysis & - & 7 & 3 & 1 \\
Anorexia & - & 3 & 1 & 1 \\
Rales & - & 12 & 1 & 4 \\
Local diminution of & - & 10 & 1 & 2 \\
$\quad$ breath sound & & & & \\
Local wheezes & - & 7 & 1 & 0 \\
Diffuse wheezes & - & 3 & 1 & 1 \\
\hline Uncesting
\end{tabular}

Uncert: uncertain; Bronch: broncholith; *: history of choking could elicit a possible choking history before the diagnosis was made in the other 14 patients. Another seven patients recalled a possible incident after the foreign body was recovered. One of the five patients in the broncholith group volunteered a choking history. Symptoms were not evaluable in patients in the acute group, because the patients were comatose or recordings of symptoms were unavailable. In the other three groups, cough, which was usually chronic and productive, led the list. Haemoptysis, if present, was mild except for one patient in the uncertain group, who concomitantly had untreated bronchial and pulmonary tuberculosis.

\section{Chest roentgenography (table 3)}

In the acute group, two patients were excluded because one had no chest film taken before the foreign body was retrieved, and the other showed advanced pulmonary tuberculosis without any other lesion which could be due to a bronchial foreign body. A radio-opaque foreign body was seen in six of the other seven patients. Inflammatory lung lesions, such as pneumonic patches or atelectatic changes were seen in three patients. In the chronic and uncertain groups, $28(85 \%)$ patients showed inflammatory changes, such as pneumonic patches, or bronchiectatic or atelectatic changes in the tributary lung distal to the bronchial foreign body. In three cases the condition was complicated by pleural effusion or empyema. Only three patients showed a foreign body on chest films. Four patients had normal chest films. In the broncholith group, all five patients showed calcified spots on chest films; however, the spots were located in the area corresponding to where the broncholiths were found in only three patients. In these three patients, the spots did not disappear after the broncholiths were removed.

Table 3. - Roentgenographic presentations" in the 4 groups

\begin{tabular}{|c|c|c|c|c|}
\hline & $\begin{array}{l}\text { Acute } \\
\mathrm{n}=7^{*}\end{array}$ & $\begin{array}{c}\text { Chronic } \\
\mathrm{n}=29\end{array}$ & $\begin{array}{c}\text { Uncert } \\
n=4\end{array}$ & $\begin{array}{c}\text { Bronch } \\
n=5\end{array}$ \\
\hline $\begin{array}{l}\text { Inflammatory } \\
\text { pulmonary lesions }\end{array}$ & 3 & 24 & 4 & 3 \\
\hline Pleural effusion & 0 & 2 & 0 & 0 \\
\hline $\begin{array}{l}\text { Loculated pleural } \\
\text { fluid collection }\end{array}$ & 0 & 1 & 0 & 0 \\
\hline Foreign body visible & 6 & 3 & 0 & 0 \\
\hline Calcified lung spots & - & 0 & - & 5 \\
\hline Normal & 0 & 4 & 0 & 0 \\
\hline
\end{tabular}

*: two patients were excluded (see text); \#: one patient could have more than one finding. Uncert: uncertain; Bronch: broncholith.

\section{Bronchoscopy}

The main indications are listed in table 4 . In the acute group, a choking history (positive history) and a visible foreign body on the chest films were the main indications. In the other three groups, a positive history remained important; however, 16 patients received bronchoscopy 
Table 4. - Main indication for bronchoscopy in the 4 groups

\begin{tabular}{lccccc}
\hline & Acute & Chronic* & Uncertain & Broncholith & Total* \\
\hline Positive history & 3 & 14 & 0 & 0 & 17 \\
Visible foreign body & 6 & 3 & 0 & 0 & 9 \\
Haemoptysis & 0 & 0 & 2 & 1 & 3 \\
Suspected endobronchial lesion & 0 & 11 & 2 & 3 & 16 \\
Suspect lung cancer & 0 & 4 & 0 & 1 & 4 \\
Unexplained chronic cough & 0 & 0 & 4 & 5 & 47 \\
\hline Total number & 9 & 29 & & & 1 \\
\hline
\end{tabular}

*: three patients had positive history and visible foreign body on chest films.

due to "suspected endobronchial lesion", e.g. recurrent pneumonia in the same area, delayed resolution of the pneumonia, pneumonia with protracted fever or toxic signs after initiation of the treatment, local wheezes or pneumonias with lung volume loss. Four patients received bronchoscopy because chest films showed lesions in which malignancy was difficult to rule out. In the chronic group, the duration of residence of the foreign body ranged from 1 month to more than $10 \mathrm{yrs}$, with a mean of 25.8 months and a median of 24 months. The delay in the diagnosis was due to absence of a choking history and invisibility of the foreign body on the chest films in 12 patients; due to the patient's ignorance of a choking history in 14; due to the physician's ignorance of a choking history in one; and due to previous unsuccessful retrieval attempts in other hospitals in two.

Table 5 outlines the locations of the foreign bodies. One patient in the chronic group had two foreign bodies. They were unrecognizable hard mineral matters, somewhat like a seashell which had been eroded and fractured into two. The nature of the foreign bodies are shown in table 6 . In the acute group, one patient aspirated 11 pieces of pear and all were in the left lung. In the chronic and uncertain groups, chicken or fish bones were most common (19 out of $29,70 \%$ ). In the broncholith group, the broncholiths were usually small; however, one patient had three large broncholiths of up to $1.2 \mathrm{~cm}$ in size.

Table 5. - Locations of the foreign bodies in the 4 groups

\begin{tabular}{lcccc}
\hline & Acute* & Chronic & Uncert & Bronch \\
\hline Rt main bronchus & 0 & 1 & 0 & 0 \\
Rt upper bronchus & 0 & 0 & 0 & 1 \\
Rt intermediate & 3 & 9 & 2 & 1 \\
$\quad$ bronchus & & & & \\
Rt middle bronchus & 0 & $2^{\#}$ & 0 & 1 \\
Rt basal bronchus & 3 & $9^{\#}$ & 1 & 1 \\
Lt main bronchus & $2^{*}$ & 3 & 0 & 0 \\
Lt upper bronchus & 0 & 1 & 0 & 1 \\
Lt lower bronchus & $2^{*}$ & 5 & 1 & 0 \\
\hline Total number & 9 & 29 & 4 & 5
\end{tabular}

*: one patient had multiple foreign bodies in left main bronchus and left basal bronchus; \#: one patient had two foreign bodies at different sites. Uncert: uncertain; Bronch: broncholith. Rt: right; Lt: left.
The foreign body was removed with a flexible fibreoptic bronchoscope in all eight patients in whom a retrieval was attempted in the acute group; in 26 of the 29 (90\%) patients in the chronic group; in all four patients in the uncertain group; and in three of the five patients in the broncholith group. No retrieval was attempted in the ninth patient in the acute group, because he was in septic shock and respiratory failure. Two patients in the chronic group recovered from pneumonia, in spite of failure of the initial flexible fibreoptic bronchoscopy to retrieve the foreign body. They did not accept another bronchoscopy and were lost to follow-up. Another patient underwent bronchotomy after both flexible fibreoptic and rigid open tube bronchoscopies had failed to retrieve the foreign body. In the broncholith group, one patient coughed up three large broncholiths within 2 weeks after fibreoptic bronchoscopy, which had failed to retrieve the foreign body but made it movable. One patient in the broncholith group was lost to follow-up after a flexible fibreoptic bronchoscopy had failed to retrieve it and a rigid open-tube bronchoscopy had failed to visualize it. One patient in the uncertain group died of sudden massive haemoptysis, 2 days after retrieval of the foreign body. This could have been due to concomitant pulmonary tuberculosis. Another patient developed lobar pneumonia several days after retrieval of broncholiths. He responded well to oral penicillin treatment at the outpatient clinic. None of the other patients had significant complications.

Table 6. - Nature of the foreign bodies in the 4 groups

\begin{tabular}{lcccc}
\hline & Acute* & Chronic & Uncert & Bronch \\
\hline Bone & 0 & 19 & 4 & 0 \\
Metallic denture & 1 & 2 & 0 & 0 \\
Tooth & 4 & 1 & 0 & 0 \\
Plastic piece & 0 & 2 & 0 & 0 \\
Plum stone & 1 & 1 & 0 & 0 \\
Pear slices & 1 & 0 & 0 & 0 \\
Lead wire & 1 & 0 & 0 & 0 \\
Car window glass & 1 & 0 & 0 & 0 \\
Unrecognized matter & 0 & 2 & 0 & 0 \\
Broncholith & - & - & - & 5 \\
Not recorded & 0 & 2 & 0 & 0 \\
\hline
\end{tabular}

Uncert: uncertain; Bronch: broncholith. 


\section{Discussion}

In 1988, McGuiRT et al. [26] reviewed their 88 cases of foreign body aspirations. The peak incidence was in the preschool age group, with only 15 patients of $12 \mathrm{yrs}$ or older. Twelve of these 15 patients were 50 yrs or older. In 1990, LIMPER and PRAKASH [8], reviewed their 33 yr experience in the Mayo Clinic, with 60 cases of non-asphyxiating tracheobronchial foreign bodies in adults. The median age was $60 \mathrm{yrs}$. In my study, ages ranged from 17-78 yrs, with mean ages of $41,51,60$ and 59 yrs, respectively, in each group. In accordance with the findings of LIMPER and PRAKASH [8], most of my noniatrogenic patients had normal sensitivity and had no reported use of alcohol or other sedatives.

LIMPER and PRAKASH [8] reported, that the most common foreign bodies were vegetable matter (17 case), dental appliances (10 case), and medical appliances ( 9 cases), whilst bone accounted for only 7 cases. In my series, bone was the most common foreign body in the chronic and uncertain groups. This could be due to different table customs in Chinese people. Chinese people do not use knives and forks. Therefore, meat is not sliced, but is chewed off the bone. In addition, many Chinese people like to eat the small pieces of meat in the fish head, around the fish spine, and of the chicken neck. These make it easy to choke, even in the absence of swallowing disturbances, alcohol or drugs use, or obvious changes in sensitivity. Bone, as a bronchial foreign body in adults, was not unusual in other reports [3, 6, 7, 9, 12, 15, 20, 25].

A history of a choking spell has been emphasized to be very important for the diagnosis [3, 8, 25]. In my chronic group, however, about half of the patients had no choking history before the diagnosis was made, and a quarter of the patients recalled no choking history even when they were traced back retrospectively. In 1957, Linton [6] reported 16 cases of long-standing intrabronchial foreign bodies, and found that only five patients volunteered a choking history, and another five recalled the relevant history retrospectively. Of the five patients whose foreign body was bone in that series, a relevant history was obtainable retrospectively in two, and no relevant history was obtainable in the other three. Jackson [3] also experienced that, of the bones removed from the bronchi, about $40 \%$ had been "overlooked" clinically for a long period of time, as compared with only about $10 \%$ of the total number of foreign bodies removed from the bronchi that were "overlooked". He thought that one of the reasons could be that a bone in the bronchus was invisible on roentgenograms in most cases. Similar results have been reported many times in the literature $[3,6,9$, $12,15,20,25]$.

The mean duration of residence of the foreign bodies in the bronchus was 25.8 months in my chronic group, which was much longer than the median stay of 10 days in the report by LIMPER and PRAKASH [8]. The symptoms and physical signs are nonspecific [7]. In my acute cases, foreign bodies such as teeth, dentures, glass were radioopaque, whilst vegetable foreign bodies, such as plum stone or pear slices, were invisible on chest film. In other groups, roentgenographic features usually reflected changes due to obstruction and infection of its tributary lungs and were nonspecific. All bones in the bronchus were invisible on chest films in my study. Four patients in the chronic group had normal chest films. In the broncholith group, even a $1.2 \mathrm{~cm}$ broncholith was invisible on roentgenogram. Therefore, nonvisualization of a foreign body on a chest film, or a normal chest film, does not rule out the diagnosis. Since either a choking history or a visible foreign body was always present in the acute cases, it was easy to diagnose. In the chronic group, even a vague choking history was very important. In clinical situations that might suggest a "suspicion of an endobronchial lesion", e.g. recurrent pneumonias in the same areas, delayed resolution of the pneumonia, pneumonia with protracted fever or toxic signs after initiation of treatment, local wheezes or pneumonias with volume loss, a bronchial foreign body should be considered in the differential diagnosis.

In the report by LIMPER and PRAKASH [8], rigid bronchoscopic retrieval of the foreign body was successful in 43 out of 44 patients, including 6 of 7 patients in whom fibreoptic bronchoscopic retrieval had failed. Among 23 patients in whom a fibreoptic bronchoscopic retrieval was attempted, the success rate was $60 \%$. They found that flexible fibreoptic bronchoscopy was particularly useful in patients with foreign bodies in the airways too distal for access with a rigid open tube bronchoscope, and in whom severe cervicofacial trauma precluded the neck hyperextension that was necessary for rigid bronchoscopic examination. In my experience, the success rate of fibreoptic bronchoscopic retrieval was $100 \%$ in the acute group, $90 \%$ in the chronic group, and $100 \%$ in the uncertain group. The result was much better than in that experienced by LIMPER and PRAKASH [8], and could have reached the success rate of rigid open tube bronchoscopy if the duration of the foreign body in the airway was considered. The improved and modified technique for retrieving foreign bodies has been published in detail elsewhere [27].

In conclusion, the clinical presentation of nonasphyxiating foreign bodies in the airway in adults is variable. The most important single diagnostic factor is a high clinical index of suspicion. While the rigid opentube bronchoscope continues to be the instrument of choice for removal of non-asphyxiating foreign bodies in the airways of adults in many hospitals, a flexible fibreoptic bronchoscope provides a valuable therapeutic option in selected conditions.

\section{References}

1. Killian G. Removal of a bone splinter from the right main bronchus by direct laryngoscopy. Munch Med Wsch 1897; 44: 86.

2. Jackson C. Observations on the pathology of foreign bodies in the air and food passages, based on the analysis of 628 cases. Surg Gynecol Obstet 1919; 28: 201-261.

3. Jackson CL. Bones as overlooked foreign bodies in the lung. Arch Otolaryngol 1930; 12: 499-507.

4. Norris CM. Foreign bodies in the air and food 
passages: a series of two hundred and fifty cases. Ann Otol Rhinol Laryngol 1948; 57: 1049-1071.

5. Cooly JC, Ginsberg RL, Olsen AM, Kirklin JW. Foreignbody bronchiectasis. J Thorac Surg 1956; 31: 615-617.

6. Linton JSA. Long-standing intrabronchial foreign bodies. Thorax 1957; 12: 164-170.

7. Jackson C, Jackson CL. Foreign bodies in the air and food passages. In: Diseases of the nose, throat, and ear. 2nd edn. Philadelphia and London, WB Saunders, 1959; pp. 849-855.

8. Limper AH, Prakash UBS. Tracheobronchial foreign bodies in adults. Ann Intent Med 1990; 112: 604-609.

9. Denney MK, Berkas EM, Snider TH, Nedwicki EG. Foreign body bronchiectasis. Dis Chest 1968; 53: 613-616.

10. Barrett CR Jr, Vecchione JJ, Loomis Bell AL Jr. Flexible fiberoptic bronchoscopy for airway management during acute respiratory failure. Am Rev Respir Dis 1974; 109: 429-434.

11. Klayton RJ, Donlan CR Jr, O'Neil TJ, Foreman DR. Foreign body removal via fiberoptic bronchoscopy. J Am Med Assoc 1975; 234: 806.

12. Lillington GA, Ruhl RA, Peirce TH, Gorin AB. Removal of endobronchial foreign body by fiberoptic bronchoscopy. Am Rev Respir Dis 1976; 113: 387-403.

13. Fieselman JF, Zavala DC, Keim LW. Removal of foreign bodies (two teeth) by fiberoptic bronchoscopy. Chest 1977; 72: 241-243.

14. Smith LJ, Khan MA. Role of fiberoptic bronchoscopy in removal of a foreign body. Chest 1977; 72: 264.

15. Ravikrishnan KP, Ting YM, Neuhaus A. Endobronchial foreign body demonstrated by xerotomography. Am Rev Respir Dis 1977; 115: 1057-1060.
16. Hiller C, Lemer S, Vamum R, et al. Foreign body removal with the flexible fiberoptic bronchoscopy. Endoscopy 1977; 9: 216-222.

17. Richardson RH, Zavala DC. Endobronchial foreign body removal using the bronchofiberscope. Ann Otol 1978; 87: $50-52$.

18. Rizzon CFC, Serero LC. Endobronchial pulp-canal reamer extracted with the fiberoptic bronchoscope. Thorax 1981; 36: 795.

19. Lee M, Fernandez NA, Berger HW, Givre H. Wire basket removal of a tack via flexible fiberoptic bronchoscopy. Chest 1982; 82: 515.

20. Wolkove N, Kreisman H, Cohen C, Frank H. Occult foreign-body aspiration in adults. J Am Med Assoc 1982; 248: $1350-1352$.

21. Case records of the Massachusetts General Hospital. Weekly clinicopathological exercises. Case 48-1983. A 14 year old boy with recurrent hemoptysis and a right lower-lobe infiltrate. N Engl J Med 1983; 309: 1374-1381.

22. McCullough P. Wire basket removal of a large endobronchial foreign body. Chest 1985; 87: 270-271.

23. Rafferty P, Fergusson RJ, Gaddie J. Polished off: an inhaled dental brush. Br J Dis Chest 1985; 79: 390- 392.

24. Leach AB. Inhalation of a minitracheotomy. Anaesthsia 1986; 41: 338.

25. Casson AG, Guy JRF. Foreign body aspiration in adults. Can J Surg 1987; 30: 193-194.

26. McGuirt WF, Holmes KD, Feehs R, Browne JD. Tracheobronchial foreign bodies. Laryngol 1988; 98: 615-618.

27. Lan RS, Lee CH, Chiang YC, Wang WJ. Use of fiberoptic bronchoscopy to retrieve bronchial foreign bodies in adults. Am Rev Repir Dis 1989; 140: 1734-1737. 